Bull. Mater. Sci., Vol. 21, No. 3, June 1998, pp. 247-249. (C) Indian Academy of Sciences.

\title{
Surface hardening of oil-hardened nonshrinking steel using ruby laser
}

\author{
A RAMALINGAM*, B J KALAISELVi ${ }^{\dagger}$, S SRIDHARAN ${ }^{\ddagger}$, P K PALANISAMY and \\ V MASILAMANI \\ Department of Physics, Anna University, Chennai 600025 , India \\ ${ }^{\dagger}$ Department of Physics, Pondicherry Engineering College, Pondicherry 605014, India \\ ${ }^{\ddagger}$ Engine Valves Limited, Chennai 600016 , India \\ MS received 26 August 1997; revised 24 March 1998
}

\begin{abstract}
Surface modification of metals and alloys using lasers has acquired considerable importance because the changes achieved are highly localized and superficial. In this process the mechanical and structural properties of the bulk are retained as such because of the high temperature gradient and high rate of change of temperature that are unattainable by conventional methods. The present report is on surface hardening of oil-hardened nonshrinking (OHNS) steel using Ruby laser in normal mode. It is found that surface hardening increases thrice the size of base material and the microstructure of the laser-heated zone changes from pearlite phase to martensite phase.
\end{abstract}

Keywords. OHNS steel; ruby laser; surface hardening; material processing; Pearlite phase; Martensite phase.

\section{Introduction}

Heat treatment of materials by lasers gains popularity because specific region with pre-determined phase changes could be achieved. Various authors have studied surface hardening of steels of different compositions and grades, employing continuously working (CW) and pulsed lasers (Avner 1974; Gnanamuthu 1979; Hugel 1988; Lampman 1981). Markarov et al (1989) studied the influence of laser and electron beam treatments on the structure transformations and abrasive wear resistance of hardened steel 20KHN3A which is widely used in the manufacturing of drilling bits and other components operating under conditions of high contact loads using $\mathrm{CW} \mathrm{CO}$ laser. Bradley (1988) theoretically studied the hardened depth obtained by scanning steel surfaces with a laser beam. The calculated depth of hardening was found to be in agreement with experimental results for three steels processed with a $\mathrm{CO}_{2}$ laser. Laser surface hardening of ferrous materials is a process used to improve the mechanical properties of highly stressed machine and tool parts. In this process only a thin layer of the surface is heated to austenization temperature prior to quenching leaving the interior of the work piece unaffected. If the power density of the laser beam is high, heat is generated at the surface at a rate higher than the heat conducted to the interior parts of the material and within a short duration the thin surface

*Author for correspondence layer will reach austenizing temperature whereas the interior of the workpiece will be at its initial temperature. Laser transformation hardening of steel is currently employed in many automobile and tool industries because of its technical advantages over the flame and induction hardening. It gives minimum distortion, ability to harden localized and inaccessible areas, high-speed processing and improved mechanical properties such as hardness, fatigue and wear resistance. Oil-hardened nonshrinking (OHNS) steel which comes under tool steel is widely used in manufacturing tools for machining and gauging such as machine screw taps, threading dies, chasers and milling cutters. Studying the surface hardening of this steel using ruby laser will be useful for manufacturing industries. The present report is on surface hardening of OHNS steel using a Ruby laser in normal mode.

\section{Experimental}

The material chosen for the study was OHNS steel, which covers under dimensionally stable steels. The percentage of carbon and its alloys in OHNS steel are: carbon, $0.95 \%$; chromium, $0.5 \%$;, $0.15 \%$; W, $0.6 \%$ and the rest is iron. The properties of OHNS steels are given in table 1. The microstructure of the specimen (parent material) is pearlitic and its microhardness $280 \mathrm{VHN}$. This material is useful for threading tools of all types, such as machine screw taps, threading dies, milling cutters, wood working tools and gauges. 
The specimen were cut into blocks of $5 \times 3 \times 1 \mathrm{~cm}$ and the roughly cut surfaces of the specimen are ground in the grinding wheel. The surface was polished by using polishing papers and alumina. The papers used for polishing are given in the increasing order. Rough polishing, $120,220,400,600$; fine polishing, $1 / 0,2 / 0,3 / 0,4 / 0$, and alumina polishing is done on the specimen using rotary wheel. The sample is etched using ferric chloride to obtain the clear grain boundaries.

The hardness of the base material is measured using Shimadzu micro hardness tester (load $200 \mathrm{~g}$ ) and found to be $280 \mathrm{VHN}$. The sample was heat treated by using Ruby laser (Laser applications, Inc., Model No. 933R 3L-2) of wavelength $694.3 \mathrm{~nm}$, pulse width $300 \mu \mathrm{s}$, output energy $1.5 \mathrm{~J}$, beam divergence $1 \mathrm{mrad}$ and one pulse per min. The specimen is fixed in an optical upright which has vertical, horizontal as well as front and back movements. The laser beam was focussed by a glass lens of focal length $30 \mathrm{~cm}$ and the depth of focus was so adjusted that there was intense heating, but below melting or vapourization. If the laser beam is focussed it causes pitting of the sample. To avoid this the distance between the specimen and the lens are adjusted by trial and error method. The specimen is coated with carbon soot to avoid reflection of the incident radiation. The optimum range of the coating thickness is found to be $0.05 \mathrm{~mm}$ to $0.1 \mathrm{~mm}$. $2 \mathrm{~mW}$ He-Ne laser is used for alignment. The sample is irradiated by Ruby laser with one pulse per min, and the hardness was measured. The diameter of the irradiated beam on the specimen is $0.5 \mathrm{~mm}$. Experiments were repeated seven times. The microhardness for different laser shots are measured. The hardness at the edges $(0.2 \mathrm{~mm}$ from the centre) and at the centres for different shots are measured and these values are given in table 2 . The values show that the hardness is

Table 1. Properties of OHNS steel.

\begin{tabular}{ll}
\hline Thermal conductivity $(\mathrm{K})$ & $24.27 \mathrm{Wm}^{-1} \mathrm{k}^{-1}$ \\
Thermal diffusivity $(\mathrm{k}: \mathrm{K} / \mathrm{pC})$ & $6.687 \times 10^{-6} \mathrm{~m}^{2} / \mathrm{s}$ \\
Emissivity & 0.8 \\
Microhardness & $280 \mathrm{VHN}$ \\
Density $(\rho)$ & $8670 \mathrm{~kg} / \mathrm{m}^{3}$ \\
Specific heat capacity (C) & $418.6 \mathrm{~J} / \mathrm{kg} / \mathrm{k}$ \\
Microstructure present & Pearlite structure \\
\hline
\end{tabular}

Table 2. Microhardness at different distances.

\begin{tabular}{lccc}
\hline & \multicolumn{3}{c}{ Microhardness (VHN) } \\
\cline { 2 - 4 } S1. No. & Edge & Centre & Edge \\
\hline 1 & 560 & 840 & 665 \\
2 & 569 & 927 & 680 \\
3 & 532 & 946 & 610 \\
4 & 520 & 908 & 670 \\
5 & 543 & 892 & 603 \\
\hline
\end{tabular}

maximum at the centre and decreases at the edges. It may be due to the gaussian distribution of the beam profile. The maximum value of microhardness is found to be $946 \mathrm{VHN}$ which shows that the hardness is about three times more than the hardness of the base material. Different laser shots are superimposed on the same spot and the microhardness was measured and the values are shown in table 3 . The hardness is increased by three times for the first shot and after that the hardness slowly increases.

Table 3. Microhardness for number of superimposed laser shots.

\begin{tabular}{lc}
\hline No. of shots (superimposed) & Microhardness (VHN) \\
\hline Base metal & 280 \\
1 & 790 \\
2 & 820 \\
3 & 840 \\
4 & 850 \\
5 & 857 \\
\hline
\end{tabular}

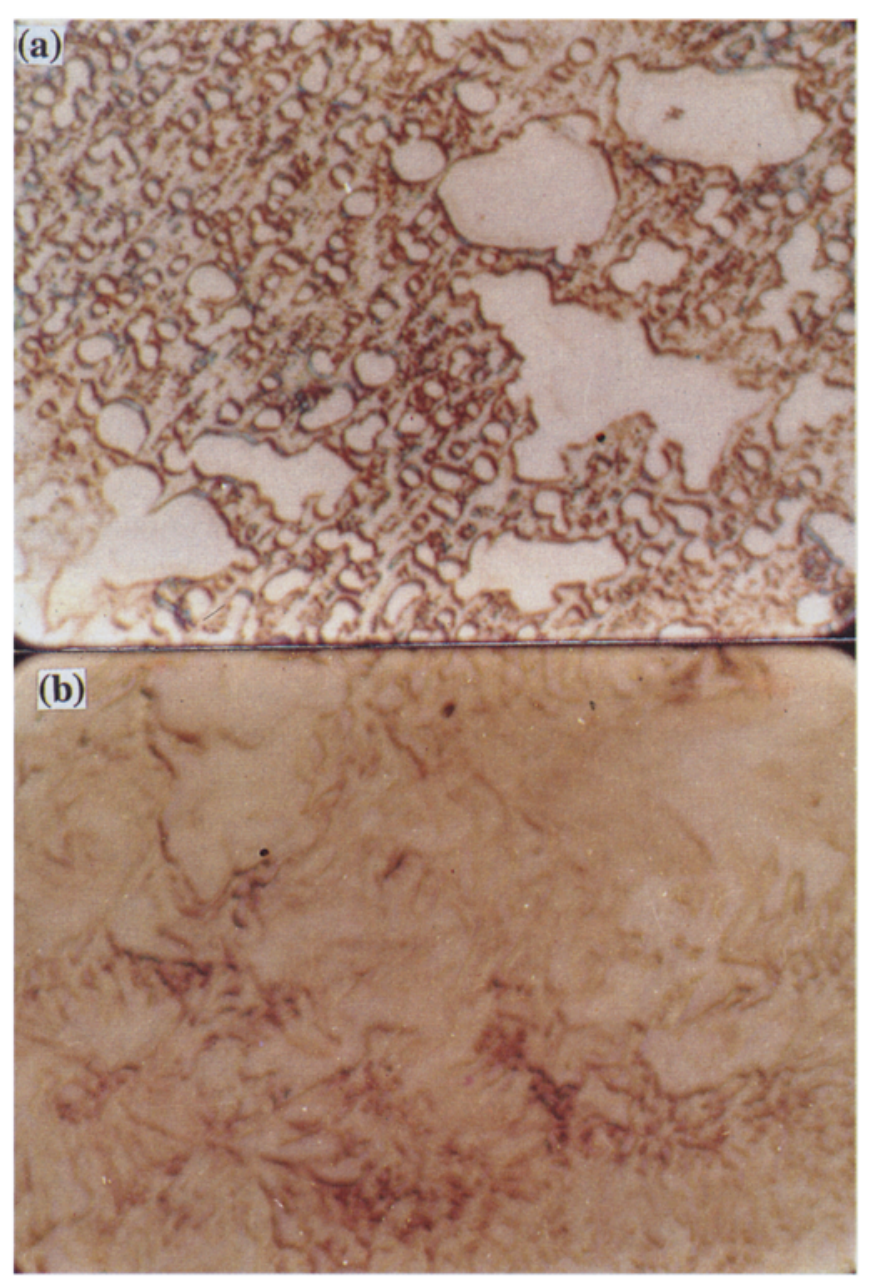

Figure 1. Microstructure of a. unhardened and b. hardened zones. 


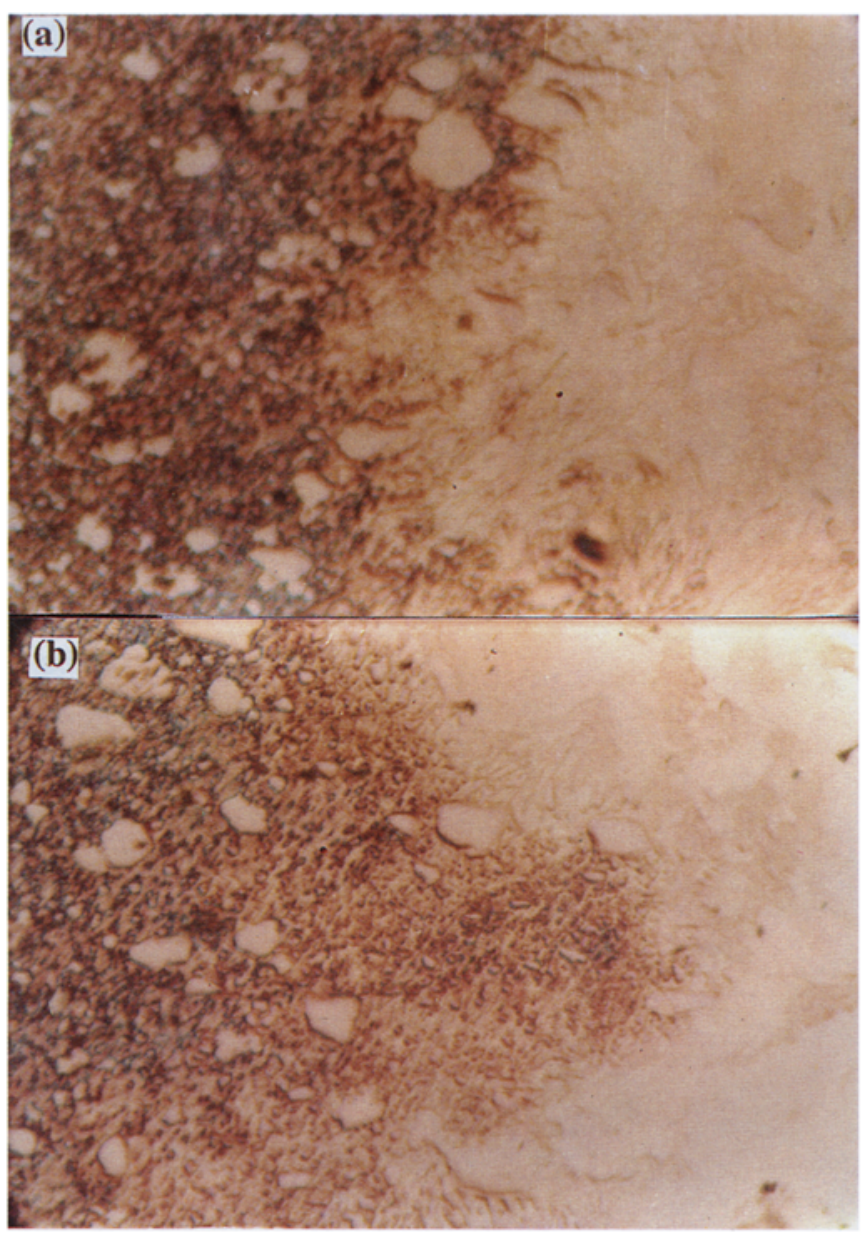

Figure 2. a-b. Microstructure of hardened-unhardened zones.

The laser-treated surface is observed through optical microscope with magnification $200 \times$ and it was found that the hardened surface has martensite phase whereas the microstructure of the parent material is pearlite phase which are shown in figures $1 \mathrm{a}$ and $\mathrm{b}$ respectively. The interface between the hardened and unhardened zones are shown in figures $2 a$ and $b$.

The surface temperature, $T$ of the specimen is calculated using the formula (Rykalin et al 1988):

$$
T=2 E P k t / A K \text {, }
$$

where, $E$ is the emissivity, $P$ the power, $k$ the thermal diffusivity, $t$ the interaction time of laser, $A$ the area and $K$ the thermal conductivity.

The hardened depth is found by using the expression (Rykalin et al 1988):

$$
Z=(4 a t / \pi)^{1 / 2}\left(T_{\mathrm{m}}-T_{\mathrm{n}}\right) / T_{\mathrm{m}},
$$

$a$ is the beam diameter, $T_{\mathrm{m}}$ and $T_{\mathrm{n}}$ are the melting and hardening temperatures, respectively.

The surface temperature and hardened depth are calculated and the values are $872{ }^{\circ} \mathrm{C}$ and $40 \mu \mathrm{m}$, respectively.

\section{Conclusion}

The microhardness of the base material is $280 \mathrm{VHN}$. The hardness obtained by furnace hardening is $680 \mathrm{VHN}$. By using ruby laser the maximum hardness achieved is 946 VHN. The laser heat treatment increased the hardness of the specimen to a larger extent. The comparison of microstructure of the laser-heated and unheated region showed a clear difference of pearlite and martensite matrices and the transition between the hardened and unhardened region was also observed. This study has showed the technical feasibility of laser surface hardening treatment to improve the wear resistance of parts of ring gear and engine valves without affecting the interior parts.

\section{References}

Avner S H 1974 Physical metallurgy (New Delhi: Tata McGrawHill)

Bradley J R 1988 J. Phys. D: Appl. Phys. 21834

Gnanamuthu D S 1979 Laser surface treatment in application of lasers in material processing, Proc. Conf. Washington DC (Ohio: ASM)

Hugel H 1988 Lasers in manufacturing (New York: SpringerVerlag)

Lampman 1981 Introduction of surface hardening of steels (Ohio: ASM International) 5 p. 259

Markarov A V, Korshunov L G, Chernenko N L, Koval N N, Kreyndel Yu Ye, Osipov I V and Chuprakova I Yu 1989 Phys. Met. Metall. 68123

Rykalin N, Uglov A, Zuev I and Kokora A 1988 Laser and electron beam material processing (Moscow: Mir Publications) 